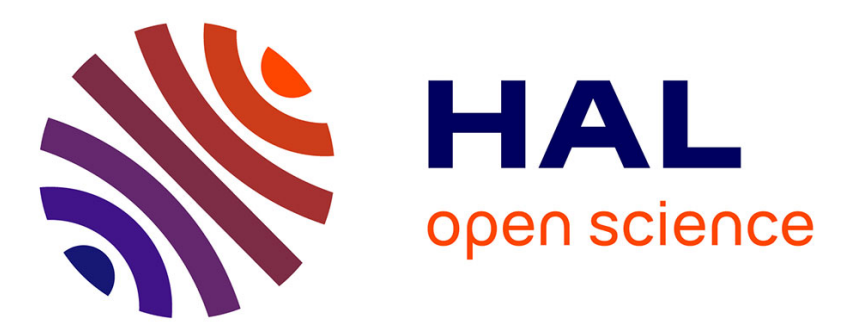

\title{
Copyright and brands in the digital age: Internalizing the externalities of meaning
}

Olivier Bomsel

\section{To cite this version:}

Olivier Bomsel. Copyright and brands in the digital age: Internalizing the externalities of meaning. Contemporary Economic Policy, 2013, 31 (1), pp.126-134. 10.1111/j.1465-7287.2011.00288.x . hal00498365

\section{HAL Id: hal-00498365 \\ https: / hal-mines-paristech.archives-ouvertes.fr/hal-00498365}

Submitted on 7 Jul 2010

HAL is a multi-disciplinary open access archive for the deposit and dissemination of scientific research documents, whether they are published or not. The documents may come from teaching and research institutions in France or abroad, or from public or private research centers.
L'archive ouverte pluridisciplinaire HAL, est destinée au dépôt et à la diffusion de documents scientifiques de niveau recherche, publiés ou non, émanant des établissements d'enseignement et de recherche français ou étrangers, des laboratoires publics ou privés. 
Olivier Bomsel

Working Paper 2010-11

Cerna, Centre d'économie industrielle

MINES ParisTech

60, boulevard Saint Michel

75272 Paris Cedex 06 - France

Tél. : 33 (1) 40519000

June 2010 


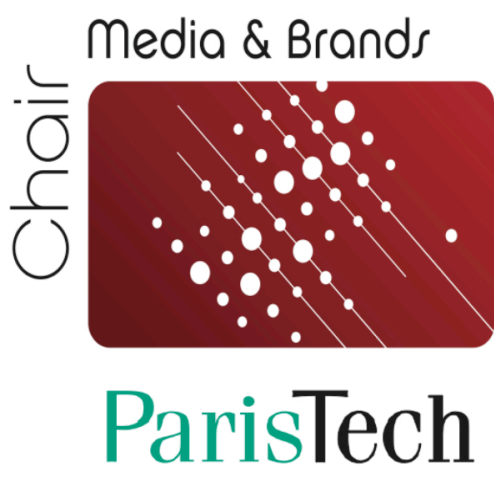

INSTITUT DES SCIENCES ET TECHNOLOGIES PARIS INSTITUTE OF TECHNOLOGY

\section{Copyright and brands in the digital age} Internalizing the externalities of meaning

Olivier Bomsel

Serciac, Cartagena, July 9th 2010

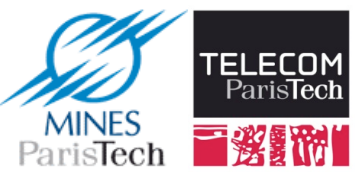

Chaire ParisTech d'Economie des Médias et des Marques

Cerna, MINES ParisTech

Tél. : 33 (1) 40519036

bomsel@mines-paristech.fr 
The adoption of binary code as the universal standard for globalized communications generates highly positive externalities often referred to as network effects. But what about meaning? What are the externalities associated with the formatting and circulation of meaning, and are they, too, all positive? Within the digital paradigm, is it really possible to separate the notion of expression - covered by copyright - from the meanings it creates? Isn't meaning heavily dependent on the concept of brand? And if so, how do copyright and trademark institutions work together to stimulate and promote meaningful information?

To answer these questions, we will look at how the meaningful forms of expression - the works - that have historically been covered by copyright generate specific types of externality, both positive and negative, giving rise to both incentive and censorship mechanisms. We will then show how the institutions of copyright and author's rights that allow the appropriation of a meaningful good also confer a brand on it, identifying its sources. This leads to mixed externalities from both directions, with the result that copyright and trademark institutions cannot be fully separated from each other.

Keywords: copyright, brand, Intellectual Property, trademark law, media economics. 
Nature of the issue

Intellectual property is a recent category (Blaug, 2005) referring to the informational nature of certain goods (Arrow, 1962) for which the definition of property rights leads to economic internalization (Demsetz, 1967). This approach allows economic analysis to explore the rational structure of the established legal institutions of copyright, patents and trademark law (Watt 2000; Landes and Posner, 2003).

As Blaug clearly shows, these institutions grew up in response to needs associated with the development of industrial techniques structured by very different logic as regards the production of information content: "It never occurred to anyone before, say the $1980 \mathrm{~s}$, that such disparate phenomena as patents for mechanical inventions, industrial products and processes (now extended to biotechnology, algorithms and even business methods), copyrights for the expression of literacy and artistic expressions in fixed form, and trademarks and trade names for distinctive products and services, could be generalized under the heading of property rights, all conferred by the legal system in relation to discrete items of information resulting from some sort of appropriate intellectual activity."1

The development of digital technologies has created new challenges for legal institutions, as illustrated by questions relating to the status of software, massive piracy, Creative Commons and no-logo ideology (Klein, 2000), calling for a fresh look at their economic functions.

Digitization (Varian, Shapiro, 1998) entails a redefinition of information as everything coded into sequences of bits. This new definition considers information not in terms of signification or semantic utility, but of transcriptability, traceability and circulation, with volume quantification taking the place of traditional representations of meaning. ${ }^{2}$ In the digital age, the term information does not imply meaningful ordering, but rather streams of bits, the pieces of code that allow transcription and logical processing of the significant component. Today currencies, laws, contracts, software, films, books, music and chemical formulae are all examples of information goods.

The adoption of binary code as the universal standard, as the alphabet for globalized communications, generates highly positive externalities often referred to as network effects (Liebowitz, Margolis, 2002). This can be roughly summed up by the fact that the more often a standard is used in writing, the greater its utility for each individual writer. Increases in utility are amplified by productivity gains in electronics (Moore's law), which broaden the range of

\footnotetext{
${ }^{1}$ Blaug (2005). Pages 71-72.

${ }^{2}$ Since the earliest days of the internet, Lawrence Lessig and his disciples have insisted that increased bandwidth leads to a corresponding rise in knowledge resources available to individuals.
} 
functionalities. But this leaves a lot of questions about meaning and signification unanswered. What are the externalities associated with the formatting and circulation of meaning and are they, too, all positive? Within the digital paradigm, is it really possible to separate the notion of expression - covered by copyright — from the meanings it creates? Isn't meaning heavily dependent on the concept of brand? And if so, how do copyright and trademark institutions work together to stimulate and promote meaningful information?

To answer these questions, we will look at how the meaningful ${ }^{3}$ forms of expression - the works - historically covered by copyright generate specific types of externality that are both positive and negative, giving rise to both incentive and censorship mechanisms. We will then show how the institutions of copyright and author's rights that allow the appropriation of a meaningful good also confer a brand on it, identifying its sources. This leads to mixed externalities from the two directions, with the result that copyright and trademark institutions cannot be fully separated from each other.

\section{Media externalities}

Copyright and author's rights ${ }^{4}$ emerged alongside print media. Historical research (Starr 2004, Birn 2007) into the development of the media clearly shows that grants of publishing privileges and authorizations to reproduce were also intended to counter the undesirable effects of the circulation of information in society. ${ }^{5}$ In each country, and in new ways for each new media, institutions encouraging the production of meaningful information have been associated with censorship mechanisms. In economic terms, the public circulation of meaningful information thus generates both positive and negative externalities. Economists are familiar with the positive side: the sharing of knowledge, artistic experience, market news, social norms, etc. These are the implicit foundations for the discussion of the economics of intellectual property (Plant, 1934; Watt, 2000; Landes and Posner, 2003).

Negative externalities including disinformation, false rumors, false science, libel, immorality, indecency, incitement to crime, sedition, etc., are less discussed, but certainly exist and, outside

\footnotetext{
${ }^{3}$ Here we use "meaningful forms" as opposed to software that is integrated into the coding system but which, for end users, is not understandable and carries no meaning.

${ }^{4}$ Unless otherwise stated, this article uses "copyright" and "author's rights" interchangeably to designate forms of ownership associated with content registered without prior official verification. The institutional designation of holders of rights is addressed at a later point.

${ }^{5}$ In the second chapter of The Creation of the Media, Paul Starr offers a comparison of the emergence of a public sphere in France and in Britain that illustrates the nature of negative externalities and each country's choice of specific means of internalization. Basic Books, New York, 2004. Pages 30-45. Raymond Birn analyses the operation, logic and impact of censorship by the crown in Enlightenment France in La Censure royale des livres dans la France des Lumières, Odile Jacob, Paris, 2007.
} 
the field of economics, they are the objects of sociological, historical and institutional analysis.

The diversity of copyright law and rules of censorship reflect different perceptions of these externalities in different societies and the different methods used for their internalization. Paul Starr thus explains that the first Boston riots of August 1765, which marked a first step towards constitutional recognition of freedom of speech, were in response to the extension to the American colonies, via the Stamp Act, of the stamp duty that was initially designed to limit the circulation of newspapers in Britain's intellectual elite. This form of censorship, he argues, was entirely unsuited to a colonial society with a high literacy rate and very reliant on the written word. ${ }^{6}$

On different grounds, contemporary students of China (Jullien, 1995) have contrasted the dialectic of ancient Greece with the Chinese art of discourse, explaining that the imperial tradition in the use of language, given theoretical expression by Confucius, emphasizes rhetorical forms leaning towards circumlocution and allusion rather than direct confrontation. Whereas the Greeks, and their heirs in North America, favor contradiction, confrontation and antagonism, both militarily and symbolically, the Chinese have always, in their language and behavior, opted instead for metaphor, for diversion, for sinuosity. ${ }^{7}$ On this basis, it could be argued that the language - the first form of expression that the state and the lettered elite prescribed for public use - internalizes the effects of censorship. Which means that neither the exercise nor the virtues of freedom of speech, understood as the right to say everything, elicits the same social judgments.

Finally, returning to the world of digital communications, recent debate concerning access to pornographic content (Australian government statements in 2007 and Steve Jobs commenting on the iPad in 2010) is a reminder that there are also negative externalities involved in the circulation of meaningful information and many ways to internalize them.

These naturally include property mechanisms, raising the question of the economic nature of copyright. More specifically, does it only concern the internalization of positive externalities or does it also internalize negative externalities, acting as a filter, a censor of media information? If so, there is a need to look into the mechanisms involved and how they should be understood.

\footnotetext{
${ }^{6}$ Ibid. Chapter 3, pages $60-65$.

${ }^{7}$ Among the many examples cited by Jullien is this one, on the art of the verbal attack: "Pointing out the chicken to insult the dog [...]. I focus on one but my real target is the other; the one is a diversionary tactic and, as such, openly displayed as a means of reaching the other, secretly". Page 57 . Which is also, to some extent, how this example works.
} 


\section{The economics of censorship}

In one of the earliest manifestation of the power of the printed word in France, the bills posted in what became known as the affaire des placards led to a bloodbath announcing the start of the century-long wars of religion. ${ }^{8}$ In a more scholarly vein, Raymond Birn's studies of royal censorship in Enlightenment France show that the circulation of texts explaining the social order on a basis other than providence was a real danger for a monarchy by divine right. ${ }^{9}$ If the legitimacy of authority is founded on the divine order, that legitimacy declines as secular explanations become more widespread. There was thus a continuing antagonism between political legitimacy and the rise of scientific thought at the beginning of the modern age in Europe. Birn's work highlights the role of France's censors in dealing with this antagonism during the seventeenth and eighteenth century, getting authors such as the Encyclopédistes to tone down texts with seditious implications. He argues that the choice of an independent, secular institution rather than a church body or one of the regional parlements enabled the royal censors to use their diplomatic skills and steer the Encyclopédistes' publishing activities without regard for religious concerns or local interests. ${ }^{10}$ The ideological and institutional process finally wore itself out with the outbreak of the French revolution and the adoption of a legal framework based on author's rights.

This example highlights two issues: first, that censorship often precedes recognition of author's rights, and second, that this recognition takes over when the market becomes a more effective means to internalize negative externalities than state intervention. Because that is what happens with copyright. Making the author or publisher legally responsible for the publication, it places an economic agent at the center of the societal effects resulting from the dissemination of meaning, and that agent may not only get part of the commercial benefits but also incur penalties for illegal publication. Copyright is thus also a censorship institution - once society adopts laws to govern publishing, publishers allow for this in their choice of works. ${ }^{11}$

Admittedly, copyright filings are not subject to prior checks as is the case with trademarks and patents, and the work is protected whatever use it may later be put to. But this only has

\footnotetext{
${ }^{8}$ In the night of October 17-18, 1543, anti-papal bills were posted on the streets of Paris and other cities in France, and even on the door of François I's royal bedchamber at his castle in Amboise. Inspired by Calvinist teachings, the bills attacked the Catholic rite of Communion. In response, the king confessed his Catholic faith and ordered persecution of Protestants, triggering the wars of religion. (Berthoud, 1973).

9 Note that the French Republic embraces a strictly secular ideology just as fiercely as the absolute monarchy did its divine right.

${ }^{10}$ A debate is currently under way in France about the role and nature of the editorial process used by Wikipedia as compared with academic knowledge institutions. Thus "Wikigrill" articles in Books magazine use counter-examples to cast doubt on the reliability of articles published on Wikipedia.

11 Paul Starr (2003) recalls how, from 1907 to 1922, the US film industry (subsequently the Motion Picture Association of America (MPAA)) replaced churches, temperance leagues and big city governments, establishing its own rules for film censorship. Pages 315-326
} 
economic implications when the work is actually published. And the chain of contractual relationships anchored in the copyright transmits not only market signals, but also the social norms embodied in law to the creative domain. Copyright is thus a structure for the internalization of both positive and negative aspects of media dissemination. An immediate consequence is that the free-riding practices used in massive copyright infringement and counterfeiting also provide channels for the circulation of otherwise censored material. The deployment of the broadband internet has opened the floodgates not only for pirating of copyright content, but also for significant media pollution in the form of pop-ups, pornographic images, false news, etc. While governments everywhere filter TV broadcasting to children and teenagers, the internet exposes them, willy nilly, to images previously for adults only. Societies and governments have given more weight to the positive externalities of digital network deployment than to the negative externalities of copyright infringement (Bomsel and Ranaivoson, 2009) and circumvention of censorship. One obvious consequence is that millions of young people have been exposed to sexually explicit material. It is hardly surprising that on the launch of the iPad as a platform for the exploitation of copyright material and stricter enforcement of rights, its creator made promises of "freedom from porn."

To conclude on this point, copyright is not only an incentive for the production of meaning and the expression of ideas of all kinds, but also a tool for sorting and censorship, for the dissuasion of information considered useless or harmful. The designation of the legal owner of rights the author or publisher - is not only designed to optimize transaction costs in the management of these rights, ${ }^{12}$ but also to identify the person legally responsible for publication. The system of author's rights allows a distinction between the individual creating a work and the person legally responsible for its social dissemination. In countries where a right of free speech is not legally recognized as such, it is a support for individual freedom, allowing the registration of all forms of expression. The publisher who purchases the rights is responsible for its publication and accountable to the market and the courts for its consequences. Somewhat differently, copyright law does not need to mention the author as such and makes the holder alone responsible for the societal consequences of the circulation of works. Whichever the case, the publisher is the gatekeeper who decides what reaches the public and who assumes the expected consequences of social circulation. ${ }^{13}$

\footnotetext{
${ }^{12}$ See Watt (2000), Chapter 6, pages 161-166.

${ }^{13}$ Richard Caves (2000) notes that only three or four of the 10,000 manuscripts Doubleday receives every year are ever published. When only novels are considered, the ratio is three or four for 15,000 (page 53). Censorship - understood here as filtering — is thus the first function of a publisher.
} 


\section{The economic issue of author/source identity:}

"Who is talking?"

How the meaning of information is structured depends on the communication protocol. ${ }^{14}$ Two fundamental protocols can be distinguished: correspondence and media communications (Bomsel, 2010).

Whether commercial or private, correspondence involves agents identified by name, who initiate and organize the circulation of information for their own purposes. The technical framework ensures identification of the parties, even before any actual exchanges, and the integrity of messages. This is an essential point: co-respondence by nature concerns the creation and exchange of signals with reciprocal anticipations of each party's utility. The information concerned serves the purposes of transactions between the parties and does not give rise to transactions outside the relationship or a fortiori to any copyright filing. ${ }^{15}$ Media communications, in contrast, involve dissemination to anonymous audiences, with the publisher deciding on the format and the publishing protocol. ${ }^{16}$ The material is covered by copyright and used for commercial purposes. Audiences infer its nature as media material from the publishing protocol — print, exhibition, public projection, radio broadcast, academic review, etc.

From the consumer's point of view, media are experience goods. Their utility depends on meaning, which cannot be judged before it is perceived. This raises the questions of the connection between the semantic value of a signal, as understood in linguistic terms, and its economic value measured in monetary terms or on the basis of utility. This issue is too complex to consider in any detail here, although it might be remembered that the great 18 th century economists did not hesitate to compose treatises on language as well as economics, suggesting possible links between the two. ${ }^{17}$ Clearly, if information is a core concern of economics, issues such as semantic productivity or the utilitarian valuation of meaning deserve attention from economists. $^{18}$

\footnotetext{
14 "Protocol" is used here in the sense of file transfer protocol.

${ }^{15}$ A commercial secret is not covered by copyright. See Landes and Posner (2003), Chapter 13, page 354 and following. Private correspondence can however be protected by copyright with a view to future publication.

${ }^{16}$ The French word for publisher is éditeur - from $e$ dare in Latin, meaning to "give forth." But what exactly does that mean when what is given forth is intangible? This is the question that lies at the heart of the present article.

${ }^{17}$ Adam Smith wrote a treaty on the origin of languages that examined precisely how names were assigned to objects - Considerations concerning the first Formation of Languages and the different genius of original and compounded languages. This was published in 1761 and republished in 1967 under J. Ralph Lindgren, ed., by The Adam Smith Library. See also J. Giacometti, "Langage et Monnaie chez Locke et Turgot", in Aspects de l'Economie Politique en France au XVIIIe siècle, a special issue of d'Economie et Sociétés, sér. PE. 1 March 1984, pages 119-137.

${ }^{18}$ Landes and Posner (2003) begin their chapter on trademark law with a review of the semantic
} 
Perceptions of meaning are highly dependent on context in terms of the semantic environment, signaling and societal judgments associated with the information supplied. This context naturally begins with the identification of the author, representing the first name, the first brand conveyed to the consumer. Just as the identification of parties is the first step in correspondence the identification of the source, the person delivering the message, is the first step in media communications.

In their very open discussion of the merits of extending copyright term, Liebowitz and Margolis (2004) note that snob or Veblen effects (Leibenstein, 1950) often come into play in connection with copyrighted goods. ${ }^{19}$ These effects nearly always relate to connotations external to the work itself, to signals or brands that structure perceived meaning. To cite one of their examples, an artist who limits the number of lithographs printed or of video copies not only increases unit value but also fosters perceptions of rarity - snob or Veblen effects - associated with his or her name and signature, amounting to a brand or imprint.

More broadly, the fact that experience goods can only be judged after consumption generates strong adverse selection and consumers are all the more attentive to any available signals as a means to reduce the risk of loss. Illustrating this, a literary prize boosts the sales of a book significantly more than would be warranted by the award itself as a signal of quality. ${ }^{20}$ This is because the increase in sales reflects not the qualitative differential between the book and others on offer, but the reduction of the risk to the buyer, reassured by the literary institution. All the signals providing consumers with this type of guidance thus carry significant weight. An information stream with no additional signal would be largely ignored, since it would spontaneously be considered no more than noise or worse, silence.

These signals, which we can call publishing signals, are very numerous, but of a subtle kind and very often a matter of connotation: they interfere with the meaning of the underlying signal, introducing complementary layers of meaning. ${ }^{21}$ Thus a political commentary conveys different meanings when it is written by one journalist rather than another and appears in one paper rather than another. The newspaper brand, which the reader associates with an editorial line and an

performance of words and expressions, aiming to show how granting rights to a generic brand name risks creating a semantic monopoly. Pages 168-172.

${ }^{19}$ The authors were reacting to the public protest of 17 well-known economists - including Nobel laureates Akerlof, Arrow, Coase and Friedman - against the Sonny Bono Act (Copyright Term Extension Act or CTEA) of 1998 that extended copyright from 50 to 70 years after the death of authors, when this Act was upheld by a US Supreme Court ruling in 2003.

${ }^{20}$ An average 237,000 copies are sold of books that win France's coveted Prix Goncourt, according to Livres Hebdo (2006), and Jonathan Littell's Les Bienveillantes (Gallimard, 2006) sold 730,000 - a figure well above the 20,000 figure considered successful for general interest books.

${ }^{21}$ Connotation is a complex semantic process that we will not go into here. It nonetheless has a considerable economic impact since it increases the utility of meaningful material. Suffice to note that John Stuart Mill, writing in 1843, considered that proper names were not connotative - a position challenged by many linguists (including those of Port Royal two centuries earlier) and by psychoanalysis. Connotation is also widely used in the commercial exploitation of brands (Bomsel, 2010). 
overall context of significations, colors the content, filling out its meaning. ${ }^{22}$

The point to emphasize here is that publishing signals contributing to the semantic value of discourse come under the economic heading of brands, which is a category distinct from copyright. Brands represent what are generally long-term investments in the signaling of meaningful goods. In addition to the copyrighted component, most experience goods thus also offer brand value that increases utility, often considerably. Contrary to received wisdom, the social value of a publishing brand is much higher than that of pharmaceutical products ${ }^{23}$ : a book by a famous writer published under a pseudonym will be less easily identified, recommended and sold than generic medication with properties well known to all prescribers. Conversely, circulation of anonymous messages is perceived as a social nuisance: in 2010, the Federal Trade Commission threatened bloggers with a $\$ 10,000$ fine for not naming sponsors, while in France there are proposals for legislation to ban anonymous blogs. Brands are thus essential components of internalizing structures for the circulation of meaning.

Brands and copyright are clearly complementary, but while it is possible to combine the two types of asset yet keep contributors of each separate as regards financing of creation, this separation is no longer possible once content is published. The situation is particularly obvious for copyright, since the use of the production alone is covered. People who download Michael Jackson songs illegally certainly infringe copyright, but the same act also constitutes abuse of the Michael Jackson trademark, which was built up with compositions and recordings and, even more, repeated investment in media communications of all kinds, in live performances, films and worldwide tours.

What the consumer ultimately gets, even in purely informational form, is not just the copyrighted content but the inseparable combination of this content with symbolic connotations stemming from the specifiers and brands that shaped the content, contributed to its meaning, and in so doing identified it as a work for consumers.

This is not a secondary issue, since it concerns the overall pertinence of an analysis of copyright as an autonomous economic institution. In a relatively recent publication, albeit preceding digitization, Richard Watt (2000) defines copyright in terms of the distinction between the expression and a "delivery good". The delivery good is a material means introducing rivalness and excludability, and making the copyrighted content accessible to consumers. Watt, like many other economists concerned with intellectual property, separates information from the medium conveying it and makes it the subject of separate economic investigation. Reasoning focuses on

\footnotetext{
${ }^{22}$ As I write this text, and despite my publishing brand (as author), I do not know whether it will be published and, if so, what signals will be associated with it.

${ }^{23}$ Landes and Posner (2003), page 54: "Brand loyalty is nowhere near as important a factor in the market for books as in the market for drugs, but it is not fully absent." This statement ignores the importance of source ("who's speaking") as a component of meaning.
} 
the incentive for creation that results from the grant of exclusive rights, for a limited period, to public use and the production of copies, setting this against the social costs of excluding certain consumers from access to protected content.

The difficulty is that creation does not in itself have any social utility if consumers do not know where it is coming from and who has authorized it. In addition, the physical medium used for copies does not have only a logistic function but also a signifying function as a vehicle for symbols, signals, and publishing brands, starting with the author's name, generating resonances with other signals and brands. And with their connotations, these make a powerful contribution to the value of the content as meaning.

\section{Copyright and brands in media industries}

What we have been saying does not mean that copyright as an economic institution is unimportant, since, on the contrary, it identifies the input providing the basis for a series of investments that bring the product to consumers. This series of investments nonetheless varies significantly according to whether the expression involved is not in itself meaningful, as in the case of software used for the operation of the technical systems it complements, or instead is meaningful, engendering the two kinds of externality - positive and negative - that we have described. It is at this point that brand institutions are involved.

The relationship between copyright and what we will call publishing brands - to emphasize their contribution to the creation of meaning - structures media industries as a whole. Publication of meaningful material has always made use of author brands to promote dissemination. Ghostwriters for Julius Caesar, Alexandre Dumas and Jack London (e.g., Sinclair Lewis) produced material for author brands that covered circulation of their texts. To take another example, the Hollywood star system centers on the actor as a publishing brand, which was initially integrated into production through long-term contracts with studios but has now become an autonomous asset, with market values that vary from one day to the next. ${ }^{24}$ This breakup is illustrated in the works of Andy Warhol, which can be seen as allegories of the fabrication of fame (The Factory), a mise en abîme of brands generated by the media.

Publishing brands certainly limit research expense and adverse selection, thereby reducing transaction costs associated with circulation of the expression. It is their trademark or trade name function. But, even more importantly, they also add a new layer of meaning with the connotations of the names and symbols they introduce.

\footnotetext{
${ }^{24}$ Caves (2000), page 89.
} 
Media can be defined as industries for the public circulation of meaningful expression that tend to internalize the effects of this circulation: if this is accepted, the unavoidable conclusion is that copyright and brand are joined inseparably. The industrial role of media is not so much to finance, assemble and disseminate meaningful material via ad hoc vehicles as it is to filter and name, to highlight and label the author, the source, and use these signals as the foundations for a connotative brand that both enriches meaning and reduces transaction costs. Media create brands that become the symbolic vehicles for expression, conferring on the work its signifying status together with its public or commercial role. This process transforms expression into a work, an opus that consumers identify as such is the core industrial function of the media. As a result, any person with a media or a public presence - already published, already authorized by a media industry - has a publishing brand that can be used to allow expression on another medium. This will then add meaning to the expression, which will circulate under a new cobrand.

In economic terms, this mechanism leads to competitive dynamics of a special kind. Once authors are identifiable, they become the holders of their own brand and manage its semantic assets, its powers of signification and prescription, alongside associated and complementary brands. This means that there are powerful currents of crossed externalities between publishing brands, which are as unpredictable as markets for the works concerned and which creativeindustry markets and contracts (Caves, 2000) seek to internalize. These externalities relate, firstly, to the connotative aspect of brands that adds new meaning — connotation — and with it new commercial value, which is not quantifiable beforehand. Secondly, they relate to the longterm impact that a success financed by a publisher can have on the individual brand of an author, an actor or an artist. While a success of this kind yields immediate benefits for publishers, they cannot - unless they have taken special action - capture the externality that is the increment to the value of the author brand. The vertical integration of Hollywood studios in the operation of the star system can be seen as one effective method for internalization of crossed externalities. More generally, the big media corporations, the studios, and the music majors are certainly most successful in achieving this internalization.

From the legal point of view, the author's brand appears all the more legitimate in that it meets the first possession criterion, being applied to a product that has already been the object of a commercial contract. ${ }^{25}$ Whether it is called a moral right, image right or a trademark, it is an asset whose value lies in the meaning it lends to the product. Media sectors from music, sports and TV to the visual arts and literature generate and internalize positive and negative externalities in the circulation of meaning not only by virtue of copyright and analogous rights

\footnotetext{
${ }^{25}$ Landes and Posner (2003) emphasize the fact that in the United States a brand can only be registered if it has already been used for a product on the market. First-Possession Rule, pages 179-186.
} 
but also through trademarks.

\section{Open questions in the economics of copyright}

These remarks concern economic issues as much as the law of intellectual property rights.

First of all they suggest that, contrary to the assumptions of copyright economics since Arnold Plant (1934), the externalities of meaningful expression are sometimes positive and sometimes negative and that property rights internalize them symmetrically. This means that the importance of copyright lies not so much in the scope of semantic, territorial and temporal exclusivity, but in the basis it provides for the development of complementary signifying assets. The signification involved is at once connotative, homogenous and coextensive with the work of expression itself, and of a transactional nature, favoring research and selection.

The second point is that there are crossed externalities between expression and publishing brands that contribute to the circulation of meaning. These externalities are already recognized in the notion of author's rights, which, unlike copyright, links expression directly to its original specifier. In a dematerialized context, these externalities are internalized by the media industry, which has the function of structuring the meaning of public expression to increase social utility. The economic importance of publishing brands is all the greater in that physical barriers to the circulation of signs have practically disappeared.

These two considerations shed some light on current strains relating to the duration of copyright and neighboring rights. Depending on whether copyright or, a fortiori, author's rights are considered primarily as incentives for creation or instead as means to consolidate publishing brands - which also concern signification, selection and social utility - their term will match that of the author's life or the life of the connotative brands concerned. The positions of Liebowitz and Margolis (2004) regarding the merits of extending copyright term and those of Landes and Posner (2002) regarding renewable copyright implicitly recognize the weight of publishing brands in the economics of copyright.

Turning to another point, a large part of the debate on the economics of copyright concerns the selection of holders. Whether the choice is between copyright and author's right or between exclusive and collective management of license rights, the general rule has been to present this in terms of minimizing related costs for rights transactions. The perspective of brand economics attached to the author's name shows the reasons for convergence in author status - moral rights - between the institutions of copyright and author's rights, while, as regards collective management of rights, it may well reduce transaction costs but can also discourage investments 
in signaling - e.g., in all kinds of publishing brands - for the same purpose.

Finally, in the debate on orphan works, whose owners cannot be located by potential publishers and which are thus not available to the general public, the question of publishing brands needs to be looked into. Google's chief economist Hal Varian suggests (2007) that publishers should be let off the hook if they have made a diligent search for the owner of the rights. This would create an exception to the general requirement, underpinning the dynamics of publishing brands, that right holders must give prior consent. It is also worth asking what social significance orphan works really have. Either their authors are totally unknown and a publisher would have little interest in circulating them without investing in signaling, which would require exclusivity, or the rights are already being used by other publishers who have invested in a publishing brand, and who would nonetheless loose their exclusive rights if the right holders cannot be identified.

In an age of dematerialized media, consideration of the economic effects attributable to publishing brands in addition to those attributable to copyright should be a valuable source of fresh impetus for research into the economics of these institutions.

\section{Bibliography}

Kenneth J. Arrow, "Economic welfare and allocation of resources for invention," in R. Nelson (ed), The rate and direction of inventive activity. Princeton University Press, Princeton, NJ, USA, 1962.

Gabrielle Berthoud, Antoine Marcourt, réformateur et pamphlétaire, du Livre des marchants aux Placards de 1534. Genève, Droz, 1973.

Raymond Birn, La Censure royale des livres dans la France des Lumières, Odile Jacob, Paris, 2007.

Mark Blaug, "Why did Schumpeter neglect intellectual property rights?", Review of Economic Research on Copyright Issues, 2005, vol. 2(1), pp. 69-74

Olivier Bomsel and Heritiana Ranaivoson, "Decreasing copyright enforcement costs: the scope of a graduated response." Review of Economic Research on Copyright Issues, vol.6 (2), 2009.

Olivier Bomsel, L'économie immatérielle. Industries et marchés d'expériences. Gallimard, Paris, 2010.

Richard Caves, Creative Industries: Contracts between Art and Commerce. Harvard University 
Press, 2000.

Harold Demsetz, "Toward a Theory of Property Rights," The American Economic Review, vol. 57, no 2, May 1967, p. 347-359.

Steve Jobs, "Folks Who Want Porn Can Buy An Android Phone," Huffington Post, April 20, 2010.

Naomi Klein, No logo: Taking aim and the brand bullies, Picador, 2000.

Bertrand Jullien, Le détour et l'accès, Stratégie du sens en Chine, en Grèce. Grasset, Paris, 1995.

William M. Landes and Richard A. Posner, "Infinitely renewable copyright," John Olin Law \& Economics working paper No. 154, (2nd series) 11-15, 2002.

William M. Landes and Richard A. Posner, The Economic structure of Intellectual property Law, Belknap, Harvard, 2003.

Harvey Leibenstein, "Bandwagon, Snob and Veblen effects in the Theory of Consumer's demand.” The Quarterly Journal of Economics, May 1950.

Stanley Liebowitz and Stephen Margolis "Network effects," in Handbook of Telecommunication Economics, dir. Martin Cave et al., North Holland, Elsevier, 2002.

Stanley Liebowitz and Stephen Margolis, "Seventeen famous economists weigh in on copyright: the role of theory, empirics and network effects," Working Paper, January 2004.

John Stuart Mill Systèmes de logique inductive et déductive, Livre I, Chapitre II, §5. London, 1843. Fr. edition, Mardaga, 1988.

Arnold Plant, "The economic aspects of copyright in books," 1 Economica, 167, 1934.

Paul Ryan, "Australia to spend \$189 million on anti-porn tech initiative," Ars Technica, August 14, 2007.

Paul Starr, The Creation of the Media, Basic Books, New York, 2004.

Hal Varian and Carl Shapiro, Information Rules, Harvard Business Press, 1998.

Hal R. Varian, "Copyright term extension and orphan works," Industrial and Corporate Change, Spring 2007.

Richard Watt, Copyright and Economic Theory, Friends or Foes? Edward Elgar, Northampton, Ma, USA, 2000. 